\title{
Pengaruh EINino pada Gelombang Signifikan di Perairan Indonesia
}

\author{
Achmad Fahruddin Rais* \\ Badan Meteorologi Klimatologi dan Geofisika \\ Jl. Angkasa I No.2 Kemayoran, Jakarta 10720 \\ Intisari
}

\begin{abstract}
Dalam penelitian sebelumnya, pengaruh ElNino terhadap gelombang signifikan tidak mampu dianalisis dengan baik karena simulasi model yang digunakan tidak mencakup periode ElNino super. Oleh karena itu, kajian ulang perlu dilakukan dengan mempergunakan data yang mencakup periode ElNino super. Sebelum dilakukan analisis, penulis menilai akurasi gelombang signifikan model wavewatch III (WW3) dengan menghitung korelasi dan root mean square error (RMSE) terhadap data gelombang signifikan satelit altimeter. Pengaruh ElNino terhadap gelombang signifikan didapatkan dari nilai korelasi antara oceanic nino index (ONI) 3.4 dengan gelombang signifikan WW3. Penulis juga menghitung rasio antara komposit gelombang signifikan saat ElNino/LaNina serta ElNino super dengan gelombang signifikan saat normalnya. Hasil penelitian menunjukkan bahwa gelombang signifikan WW3 yang digunakan memiliki akurasi yang baik pada perairan Indonesia. ElNino dan LaNina memiliki pengaruh yang kuat terhadap gelombang signifikan di Laut Jawa dan Selat Sunda pada periode Desember-Januari-Februari (DJF). ElNino (LaNina) dapat mengurangi (menambah) tinggi gelombang signifikan sampai 30\% dari normalnya di Laut Jawa dan Selat Sunda. Pada kasus ekstrim, ElNino super mampu mengurangi tinggi gelombang signifikan sampai 50\% terhadap normalnya.
\end{abstract}

\begin{abstract}
In the previous studies, the influence of ElNino on significant waves was not able to be analyzed properly because the simulation model used did not cover the super ElNino period. Therefore, a new research needs to be done based on data in the period of super ElNino. Before analyzing, I assess the accuracy of wavewatch III (WW3) model significant wave by calculating correlation and root mean square error (RMSE) on significant wave of the altimeter satellite. The influence of ElNino on significant waves is obtained from the correlation between the oceanic nino index (ONI) 3.4 and the significant waves of WW3. I also calculate the ratio between significant wave composites of ElNino / LaNina and ElNino super events towards normal significant waves. The results show that the WW3 significant wave has good accuracy in Indonesian waters. ElNino and LaNina have a strong influence on significant waves in the Java Sea and Sunda Strait at period of December-January-February (DJF). ElNino (LaNina) is able to reduce (increase) the significant wave height until $30 \%$ to the normal condition in Java Sea and Sunda strait. In extreme cases, super ElNino is able to reduce a significant wave height until $50 \%$ to the normal condition.
\end{abstract}

Keywords: ElNino; LaNina; significant wave.

*Corresponding author: achmad.rais@bmkg.go.id

http://dx.doi.org/10.12962/j24604682.v15i2.4317

2460-4682 (C)Departemen Fisika, FSains-ITS

\section{PENDAHULUAN}

Gelombang signifikan adalah tinggi gelombang laut yang sama dengan tinggi rata-rata dari $1 / 3$ gelombang-gelombang laut tertinggi pada pengamatan visual [1]. Gelombang signifikan di perairan Indonesia dipengaruhi oleh interkasi fenomena atmosfer-laut [2]. Salah satu fenomena tersebut adalah ElNino. ElNino merupakan peristiwa pemanasan lautan skala besar di Samudera Pasifik Ekuator setiap beberapa tahun [3]. Penelitian pengaruh ElNino terhadap gelombang laut di perairan Indonesia masih terbatas. Salah satunya adalah penelitian Kurniawan [4] yang membuktikan pengaruh ElNino terhadap gelombang signifikan tidak kuat berdasarkan data model WINDWAVE-05 periode tahun 20002010. Penelitian tersebut tidak mampu menganalisis dengan baik karena periode penelitian tidak mencakup masa super ElNino [5]. Oleh karena itu, penulis akan mengkaji ulang pengaruh ElNino terhadap gelombang signifikan di perairan Indonesia dengan periode yang mencakup peristiwa ElNino super. 


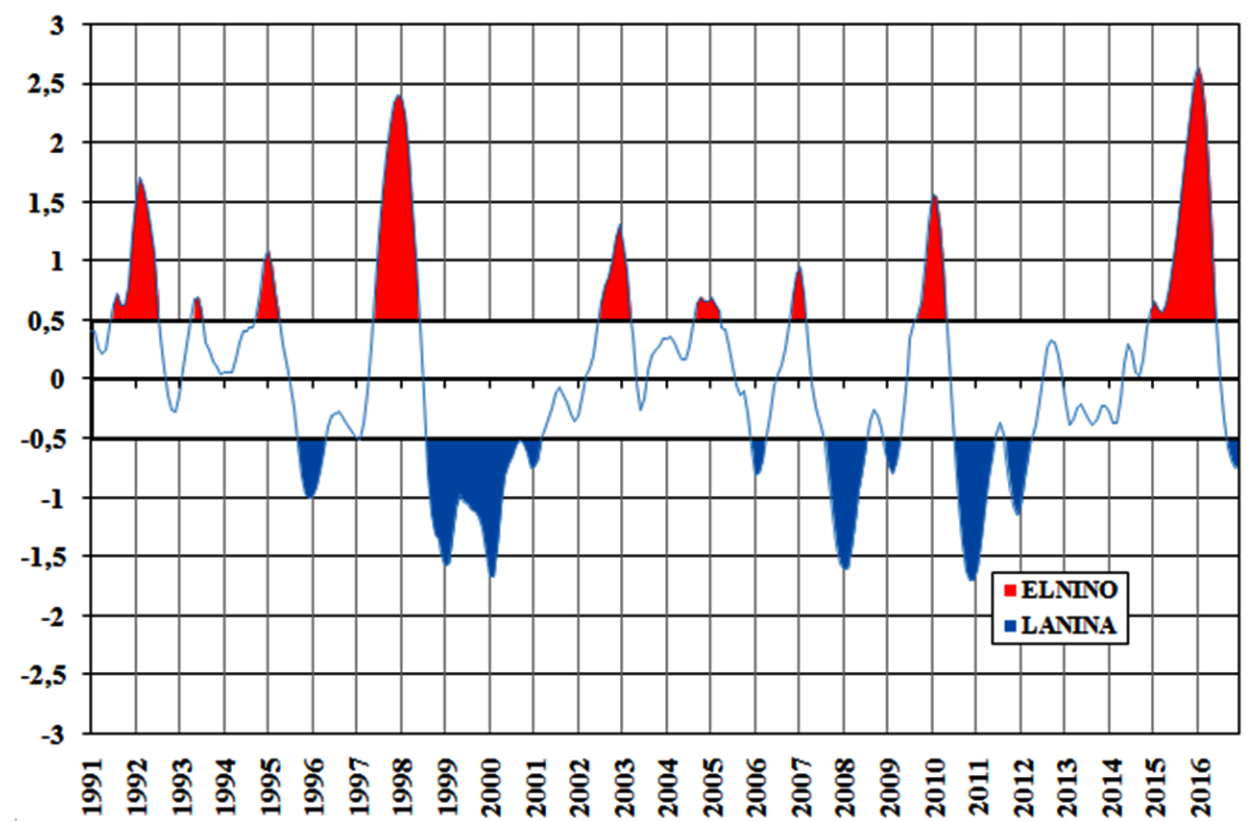

Gambar 1: Indeks Nino 3.4 saat ElNino yang menunjukkan periode ElNino (merah) dan LaNina (biru).

\section{METODOLOGI}

Penulis menggunakan data arah dan tinggi gelombang signifikan model gelombang Wavewatch III (WW3) dengan resolusi $0,125^{\circ} \times 0,125^{\circ}$ pada periode tahun $1991-2016$ yang diperoleh dari Badan Informasi Geospasial (BIG). Cakupan data model pada luasan $15^{\circ} \mathrm{N}-20^{\circ} \mathrm{S}$ dan $90^{\circ} \mathrm{E}-145^{\circ} \mathrm{E}$.

Dalam periode yang lebih pendek, gelombang signifikan model WW3 telah diuji terhadap estimasi gelombang signifikan satelit altimeter pada tahun 2000-2008 dengan nilai korelasi 0,77 - 0,94 [6]. Oleh karena itu, penulis menghitung ulang koefisien korelasi dan root mean square error (RMSE) gelombang signifikan model WW3 terhadap data estimasi gelombang signifikan satelit altimeter gabungan (Jason-1, Envisat, Jason-2 dan Cryosat-2) dengan resolusi $1^{\circ} \times 1^{\circ}$ pada periode 1991-2016.

Setelah pengujian, pengaruh ElNino terhadap curah hujan dihitung dengan mengkorelasikan antara anomali gelombang signifikan model WW3 terhadap data oceanic nino index (ONI) 3.4. Data ONI didapatkan dari National of Atmospheric Administration (NOAA). Korelasi dihitung dalam periode Desember-Januari-Februari (DJF), Maret-April-Mei (MAM), Juni-Juli-Agustus (JJA) dan September-Oktober-Nopember (SON). Penulis juga menghitung rasio perbandingan gelombang signifikan antara saat ElNino dan LaNina terhadap normalnya. Adapun rumusnya:

$$
\frac{H s_{E}-H s}{H s}
$$

dengan $\mathrm{Hs}_{E}$ adalah gelombang signifikan saat ElNino/LaNina, Hs adalah klimatologi gelombang signifikan.

\section{HASIL DAN DISKUSI}

Grafik dalam Gambar 1 memperlihatkan Elnino terjadi sebanyak 9 kali kejadian, sedangkan LaNina sebanyak 8 kali kejadian. Dua ElNino super tampak pada gambar tersebut yang terjadi pada bulan Oktober 1997 sampai Februari 1998 dan Oktober 2015 sampai Maret 2016. Lain halnya LaNina, keberadaan LaNina super tidak tergambarkan karena nilai indeksnya tidak mencapai $-2^{\circ} \mathrm{C}$.

Pada Gambar 2, korelasi tertinggi bernilai 0,7-0,8 antara gelombang signifikan keluaran model WW3 dengan gelombang signifikan satelit altimetri berada di Laut Cina Selatan dan barat laut Papua. Korelasi terendah yang bernilai 0,40,5 terdapat di Laut Sulawesi, perairan barat Kalimantan dan barat Sumatera. Semua korelasi bernilai positif yang menunjukkan bahwa pola tinggi gelombang signifikan WW3 tidak berkebalikan terhadap gelombang signifikan satelit altimetri. RMSE umumnya bernilai 0,1 - 0,7 meter. Sebaran nilai terbesar RMSE terdapat di Samudera Pasifik dan Samudera Hindia.

Pada periode MAM, JJA dan SOM, EINino tidak memiliki hubungan yang kuat terhadap gelombang signifikan. Nilai korelasi antara kedua variabel tersebut lebih kecil dari 0,5. Akan tetapi saat periode DJF pada Gambar 3, hubungan yang kuat terlihat di Laut Jawa dengan nilai korelasi berkisar antara 0,50,6. Dalam luasan yang lebih sempit, nilai korelasi yang sama juga tampak di Selat Sunda dan Samudera Hindia Selatan sebelah timur laut Pulau Christmas.

Gambar 4 bagian kiri memperlihatkan bahwa rasio perbandingan gelombang signifikan saat ElNino terhadap klimatologi gelombang signifikan bernilai -30\% di Laut Jawa. Nilai negatif tersebut menandakan bahwa EINino mengurangi gelombang signifikan sebesar 30\%. Di Selat Sunda, pengaruh gelombang ElNino tampak lebih kecil dari pada di Laut Jawa 


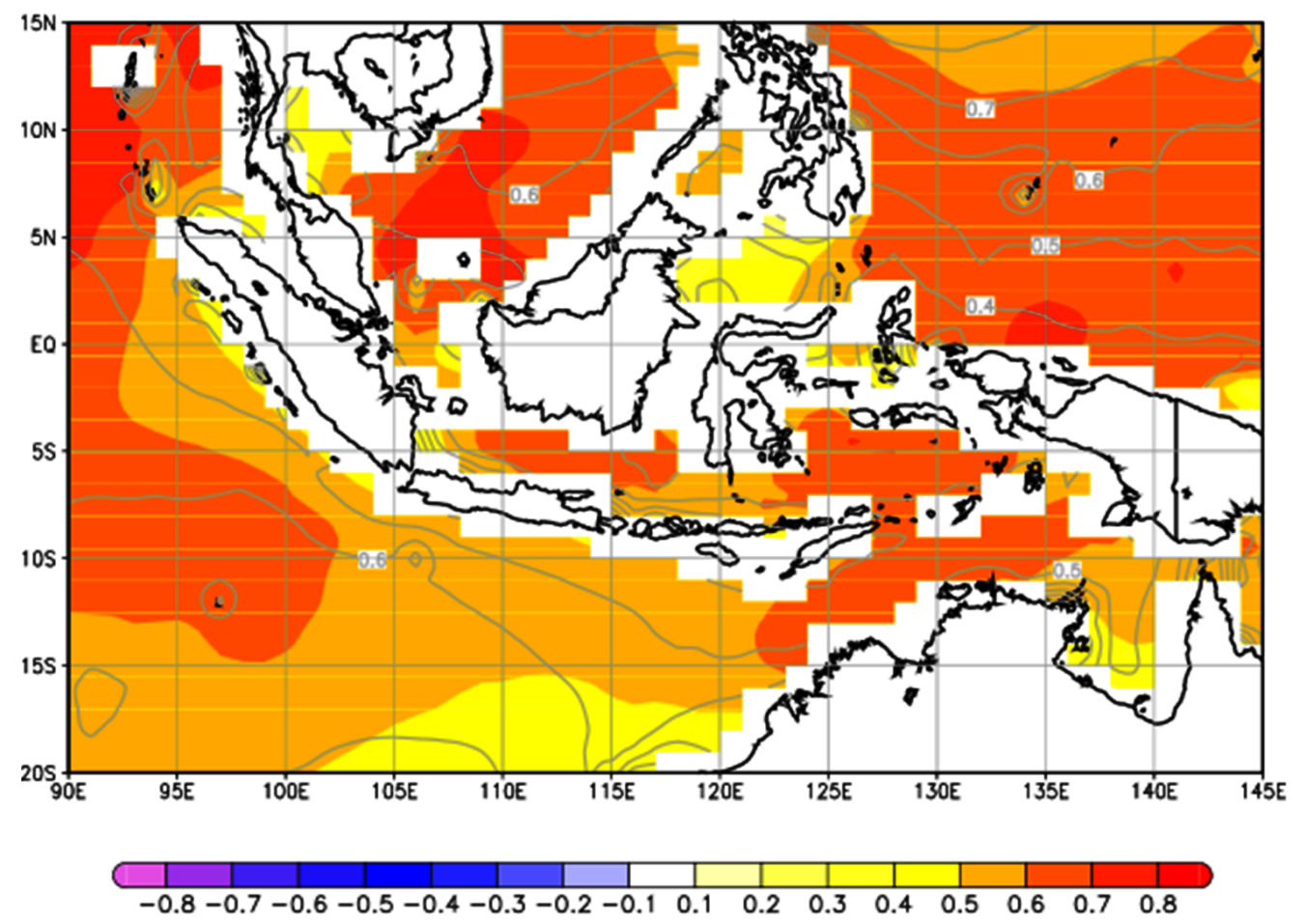

Gambar 2: Koefisien korelasi (gradasi warna) dan RMSE (kontur) antara gelombang signifikan WW3 dengan gelombang signifikan satelit altimeter.

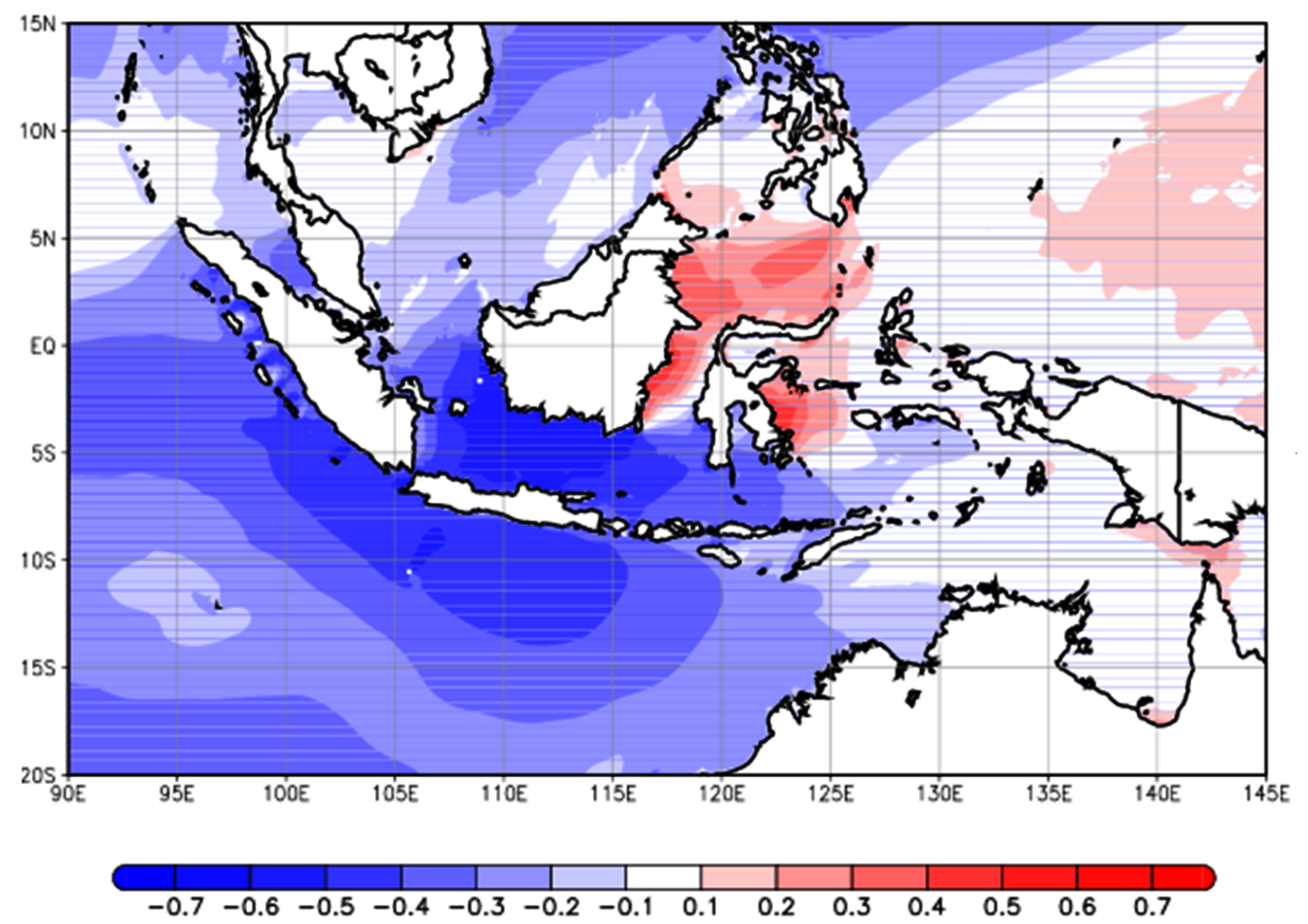

Gambar 3: Koefisien korelasi (gradasi warna) antara gelombang signifikan WW3 dengan indeks Nino 3.4 pada periode DJF. 

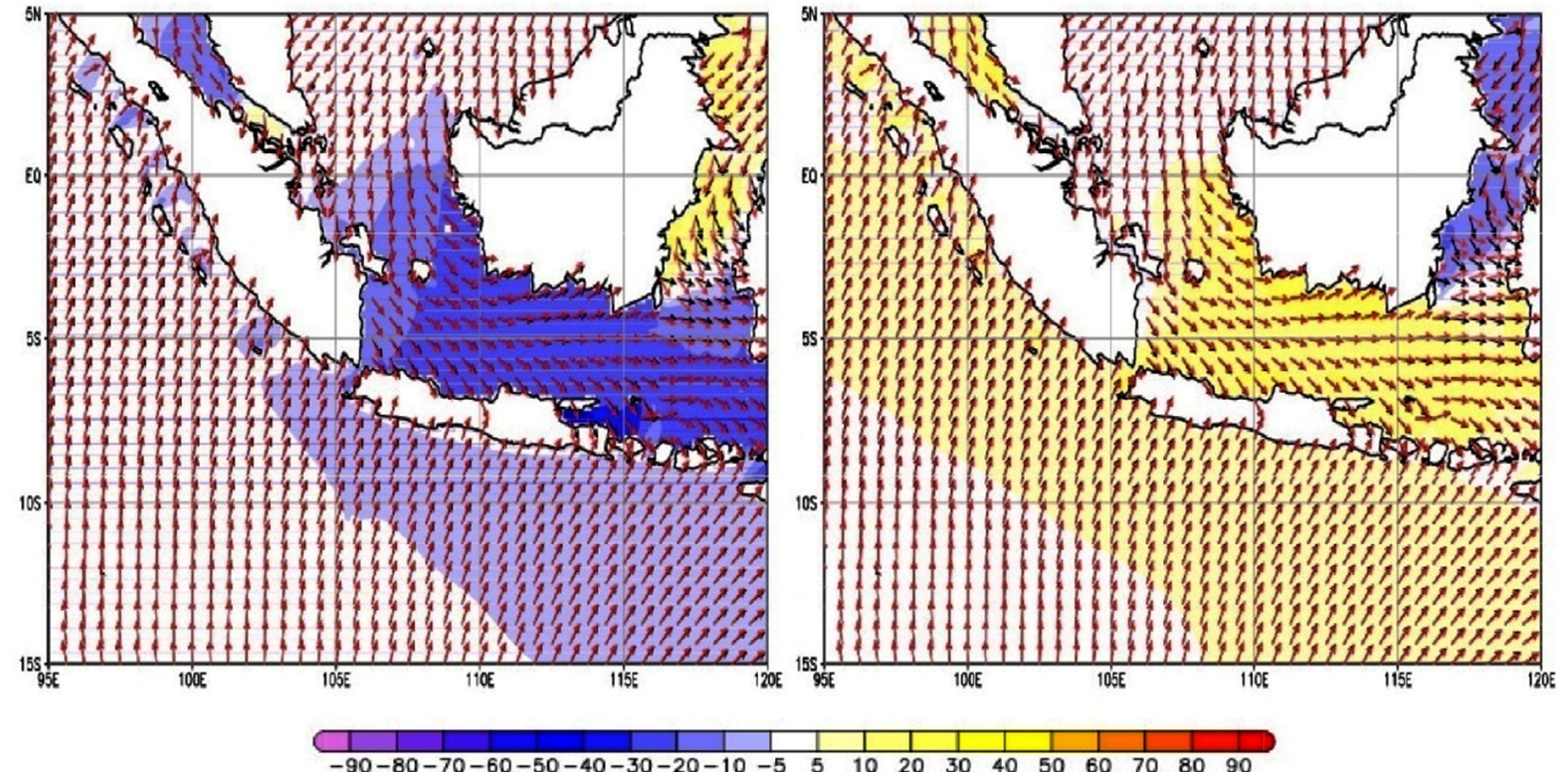

Gambar 4: Rasio perbandingan gelombang signifikan (\%) saat ElNino (kiri) dan LaNina (kanan) terhadap normalnya dan arah gelombang saat EINino/LaNina (panah merah) serta saat normalnya (panah hitam) di periode DJF.
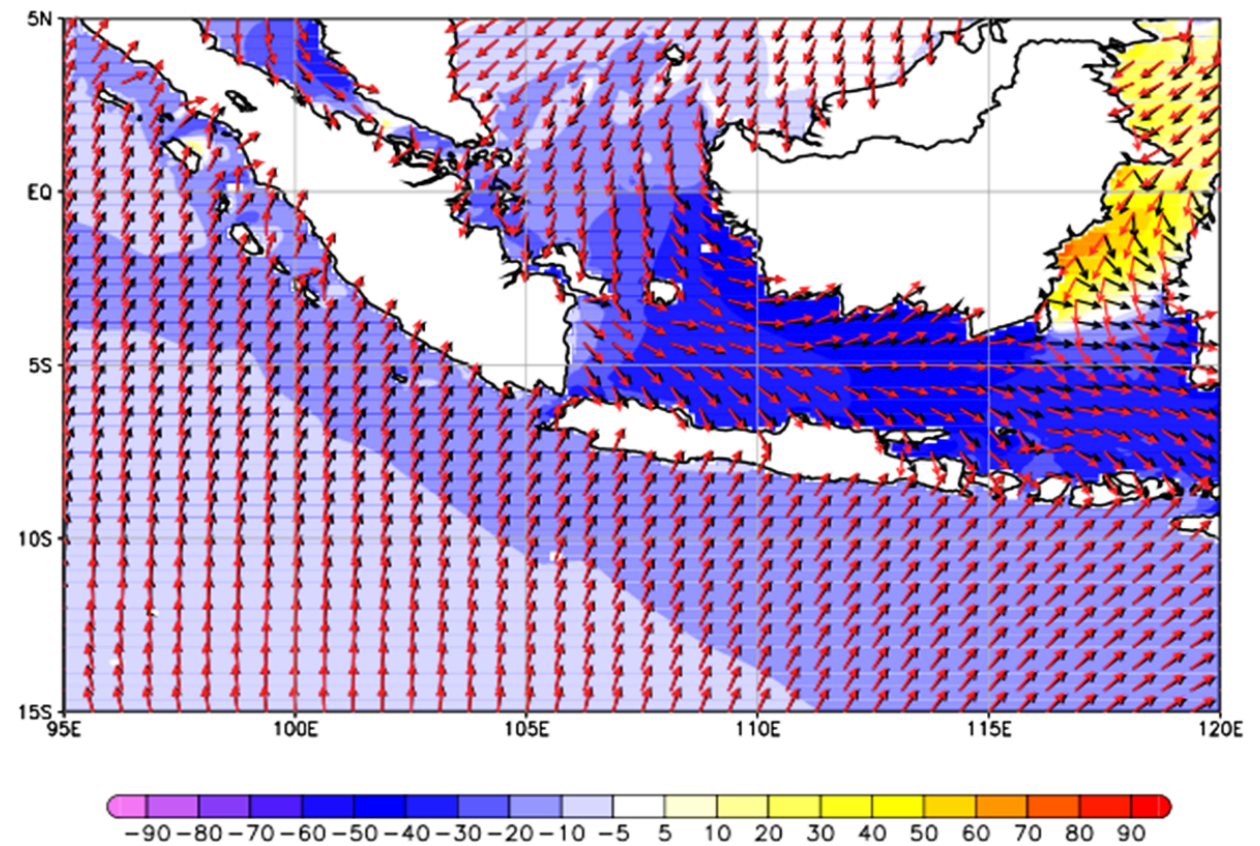

Gambar 5: Rasio perbandingan gelombang signifikan (\%) saat ElNino super terhadap normalnya dan arah gelombang saat ElNino super (panah merah) serta saat normalnya (panah hitam) di periode DJF.

dengan nilai rasio mencapai $-20 \%$. Arah gelombang signifikan saat ElNino juga tidak berbeda dengan arah klimatologi gelombang signifikan di kedua periran tersebut.

Lain halnya saat LaNina, Gambar 4 bagian kanan memperlihatkan nilai rasio perbandingan antara gelombang signifikan saat LaNina terhadap klimatologi gelombang signifikan sebesar 20\% pada bagian tengah laut Jawa dan 30\% pada Laut
Jawa dekat pulau Kalimantan dan Pulau Jawa. Nilai rasio tersebut menandakan bahwa LaNina menambah tinggi gelombang signifikan sebesar 20-30\%. Sedangkan di Selat Sunda, LaNina juga mampu meningkatkan tinggi gelombang signifikan dengan rasio perbandingan mencapai $20 \%$. Arah gelombang signifikan saat LaNina juga sama dengan klimatologinya. 
Gambar 5 memperlihatkan penurunan tinggi gelombang signifikan pada saat ElNino super di Laut Jawa. Penurunan tinggi gelombang signifikan terbesar terjadi di perairan selatan kalimantan dan Laut Jawa bagian timur dengan rasio perbadingan mencapai $40 \%-50 \%$ pada periode DJF. Pada Laut Jawa bagian barat dan tengah, tinggi gelombang signifikan mengalami penurunan sebesar 30\%-40\%. Sedangkan pada Selat Sunda, pengaruh EINino super mampu menurunkan tinggi gelombang signifikan sampai $40 \%$. Adapun arah gelombang signifikan tidak banyak mengalami perubahan saat ElNino super.

\section{SIMPULAN}

Gelombang signifikan WW3 yang digunakan memiliki akurasi yang baik pada perairan Indonesia. EINino dan LaNina memiliki pengaruh yang kuat terhadap gelombang signifikan di Laut Jawa dan Selat Sunda pada periode DJF. ElNino (LaNina) dapat mengurangi (menambah) tinggi gelombang signifikan sampai $30 \%$ dari normalnya. Pada kasus ekstrim, ElNino super dapat mengurangi tinggi gelombang signifikan sampai $50 \%$ terhadap normalnya.
[1] WMO, "Guide to Wave Analysis and Forecasting", Second Edition, Geneva, Switszerland, 1998.

[2] R. Rachmayani, N.S. Ningsih, H. Ramadhan, S. Nurfitri, "Analysis of Ocean Wave Characteristic in Western Indonesian Seas Using Wave Spectrum Model", MATEC Web of Conferences 147, 05001 DOI: 10.1051/matecconf/201814705001, 2018.

[3] C. Wang, C. Deser, J.Y. Yu, P. DiNezio,and A. Clement, "El Nio and Southern Oscillation (ENSO): A Review" in "Coral Reefs of The Eastern Tropical Pacific", Springer, DOI 10.1007/978-94-
017-7499-4-4, 2016

[4] R. Kurniawan, "Karakteristik Gelombang Laut dan Daerah Rawan Gelombang Tinggi di Perairan Indonesia”, Tesis, Universitas Indonesia, 2012.

[5] L.C. Hong, "Super El Nio", Springer, 2016.

[6] I. Sofiyan, dan A.B. Wijanarto, "Simulation of Significant Wave Height Climatology Using Wavewatch III", International Journal of Geoinformatics, vol.6, no.4, pp. 13-19, 2010. 